\title{
The Dialectical Opposition between Traditional Philosophy and Cultural Education
}

\author{
Shen Qi \\ China Jiliang University \\ Hangzhou, China
}

\begin{abstract}
The main purpose of this paper is to study the guiding role of dialectical opposition of Chinese traditional philosophy in cultural teaching, especially in the teaching of Chinese traditional culture. Based on the discussion of the dialectical opposition of Chinese traditional philosophy, this paper mainly focuses on analyzing the origin and characteristics of dialectical opposition and its relationship with culture, expounds its important role in cultural teaching, finally concludes that dialectical opposition has deeply and profoundly influenced Chinese traditional culture. Therefore, in-depth study of this thinking will help educators to better understand traditional culture and will greatly contribute to the development of teaching and practice activities in cultural education.
\end{abstract}

Keywords-Philosophy; Dialectical opposition thought; Education; Culture education

\section{INTRODUCTION}

Nowadays, culture teaching has become a topic of much discussion in the field of education, in which traditional culture education has been paid more attention by many scholars. The thought of dialectical opposition in traditional philosophy is an important part of Chinese philosophy. At the same time, it has deeply influenced the Chinese culture, especially the traditional culture. From three aspects of the origin and content of the thought of dialectical opposition, the influence of the thought of dialectical opposition on the form of traditional culture and the enlightenment of the thought to culture and education, this paper probes into the relationship among the position, content and culture and education of the thought.

\section{THE DIALECTICAL THOUGHT OF OPPOSITION IN TRADITIONAL PHILOSOPHY}

The thought of dialectical opposition in traditional philosophy can be divided into two parts: the thought of simple dialectics and the thought of relativism. As a kind of deep thought engraved in the psychology of the Chinese nation for a long time, it has deeply influenced many aspects of Chinese society. And for the Chinese nation to observe the orientation of the problem as well as social science and natural science research, have played a great role in restricting.

\section{A. The thought of simple dialectics}

The origin of the thought of simple dialectics can be traced back to the remote prehistoric clan period, at that time, the ancestors had already expressed the understanding of the unity of opposites of the universe with the design of the gossip. The concept of yin and yang is a dualistic theory that regards the unity of opposites of yin and yang as the fundamental attribute of objective things, which still prevails in Chinese society today.

"As far as the Chinese traditional dialectical philosophy is concerned, before the Spring and Autumn period and the warring States period, this kind of philosophy paid attention to the harmonious unity and mutual transformation of 'there is no isolation of things, and the unity of heaven and man'. Among them are the Confucianists and Taoists of the Pre-Qin period. Although the philosophy of life of the two families is quite different, and there are great differences in political ideas, but in the attitude to the "unity of heaven and man" is a rare agreement. It can be said that the unity of heaven and man is an important and constant cornerstone of the development of Chinese traditional philosophy. "

"Heaven" in "the unity of heaven and man" refers to the natural heaven or heaven's way, "man" refers to human or humanity, "the unity of heaven and man" refers to the similarity between heaven and humanity and the unity between each other. This is not only the cornerstone of traditional philosophy, but also a very important proposition in the history of ancient Chinese ideology and culture.

\section{B. Relativism}

Relativism is a trend of thought opposite to dogmatism. The representative figure in China is Chuang Tzu of Taoism. Zhuangzi's most famous relativism thought is "Qi material theory" and "Qi right and wrong", "'all things are one' is the basic proposition of Chuang Tzu's relativism. It is the main thought that runs through his philosophy system, "he has been advocating to clear up the differences between foreign things from the angle of" Tao ", and he thinks that there is no definite standard for human knowledge. Even it is doubtful whether one can really get knowledge. 


\section{IMPACT ON LANGUAGE AND CULTURE}

\section{A. Philosophy and language}

Because the meaning of the word can intuitively reflect the subjective understanding of the surrounding things of the group using the language, so the meaning of the word can be said to be the code of national ideology and culture. Therefore, as an important ideological concept of the Chinese nation, the idea of the unity of nature and man in the process of people's understanding of the world, inevitably reflected in the Chinese word meaning system, which makes a lot of Chinese word meaning extended results are not found in many other languages.

On the traditional philosophy of the dialectical opposition to the impact of language and culture, the academic community has long been made a more accurate summary. Chang Jingyu thought: "the traditional dialectical philosophy and relativism thought, reflected in the vocabulary, made it appear a large number of words with opposite meanings and relative structure." This dialectical opposition has influenced the evolution of the Chinese language, so that the Chinese language has two important characteristics: the symmetry in the vocabulary structure and the coupling in the syllable. "

The academic circles regard this kind of words as the dialectical opposite cultural words. This kind of word reflects Chinese traditional dialectic thought and relativism thought from the aspect of Chinese vocabulary. In the long process of evolution, the writing is influenced by the simple dialectical ideas, which makes the vocabulary show a kind of emphasis on connection and harmony. However, the relativism characterized by the absence of fixed standards and the elimination of opposites makes the Chinese vocabulary present a flexible attitude of change.

Because vocabulary can best reflect the change of ideology and culture, the author will mainly use Chinese vocabulary as an example to demonstrate the impact of dialectical opposition on Chinese language and culture.

\section{B. Philosophical thought and mode of thinking}

The philosophical thinking of a nation will influence the thinking mode of the nation imperceptibly, and the dialectical opposition thought in the traditional Chinese philosophy will also influence the thinking mode of the Chinese nation in the process of continuous inheritance. And makes it take on the hobby harmonious symmetrical, circulationism color and so on characteristic.

\section{1) Love harmony and symmetry}

In the eighth century, the Japanese master Hongfa made such a statement about the reflection of China's dialectical opposition concept in Chinese culture: "every article has to be according to its own, and it is true that things should not be isolated, and there must be a match." To if the upper and lower, respect and inferiority, there and no, the same and different, so and so, all belong to the genus. In addition, it must be divided into categories: one, two, three, four, the like, the east, the south, the north, the west, the north and the west, the like, the princes, Wang, Qing, the position, and the like. And in the couplet, double rhyme, too many kinds of things, can not be prepared to say. "

From the above materials can be found, one of the characteristics of the Chinese nation's thinking is the love of harmony and symmetry.

The Chinese people's interest in harmony and symmetry is reflected in the language and culture, the first point is manifested in the use of a large number of words in pairs. For example, the names of some Chinese counties, such as Baxian and Tongxian, are not called "Ba" or "Tong" directly, but are called together with the word "County" behind them. The second point is the extensive use of four-character vocabulary. When we speak of idioms, four words are bound to come into our minds. This is because the Han people have the habit of generalizing the commonly used allusions and idioms into four characters. If an idiom itself is less than four or more words, it will be expanded or reduced to four words. For example, the etymology of "bouncing the crown and celebrating" is "playing the crown", and the etymology of "like birds and animals dispersing" is "birds and animals scattered". The third point is the use of a large number of dual structures. "'pair' refers to the opposite, 'dual' is a pair, 'dual' is a group of words or sentences with symmetrical structure and equal number of words, to express similar, relative, opposite meaning of a rhetorical form. "more common in the couplet, proverbs and other language forms, since the Yuan, Ming and Qing dynasties, literary works and storytelling performances are often used as the title of the dual form to sum up the main content of the work. In the contemporary newspaper news, the duality is also more common in the news headlines.

\section{2) Cycle theory color}

From the fire source of Heraclitus, the ancient Greeks absorbed the changing and cyclic view that "everything flows", "the world is a living fire, burning at a certain level and extinguishing at a certain level". And still exist in the western thinking tradition, and the Chinese nation thinking since ancient times also has the color of the cycle theory and compensation theory, its source is the ancient simple dialectics

Chinese idioms have a large number of words to express the concept of this cycle and complementary, such as joy and extreme sorrow, negative extreme, sweet, strong and soft, yin and yang complement each other. From the examples of the above idioms, it is not difficult to find that these words have the words "extreme", "do", "Ji" and so on, expressing a kind of circular, opposite and complementary way of thinking.

This law of changing back and forth between duality can be traced back to the Book of changes, in which Yin and Yang, as a category of opposition, summed up all the phenomena of opposition in the world. The thought of Yin and Yang is not only the important cornerstone of Chinese philosophy and religion, but also the unique dualistic culture of China. In the warring States period, the Taoist Lao Tzu had realized that there are two opposite aspects of things, and the movement of things is the process of moving in the opposite direction. He summed up this law of motion as "the opposition, the movement of the Tao." His view that the positive and negative sides of things can be transformed into each other is marked by relativism and cyclists. 
The second is "complementary" mode of thinking. Lao Tzu once said that "one yin and one yang are called Tao," because the way of unity requires the mutual integration of yin and yang. This mode of thinking also originates from the theory of yin and yang in Zhouyi, in which yin and yang are not only a pair of opposite categories, but also a pair of harmonious things that can complement each other. Later, the theory of the five elements of the Yin and Yang schools of the warring States period extended the theory of complementarity to a great extent.

The Chinese advocate harmony, that everything has its own attributes, different attributes combined to produce good or bad results, which is not only reflected in the superstition of the five elements of the number, but also reflected in many therapies in traditional Chinese medicine. After Buddhism was introduced into China, it brought another kind of compensation principle, that is, the concept of "retribution" of causal samsara. People believe that the good and evil they do when they are alive will have a process of accumulation of quantitative change, to a certain extent, will lead to qualitative change, causing people to go to hell or die the results of bliss.

\section{INSPIRATION TO CULTURE AND EDUCATION}

\section{A. Importance of cultural education}

This year, the state attaches great importance to cultural education, and has repeatedly proposed in important conferences and documents to improve the existing cultural and educational system.For example, at the third Plenary session of the 18th CPC Central Committee in 2013, it was proposed to improve Chinese excellent traditional culture and education. To improve the aesthetic and humanistic quality of students. In April of the following year, the Ministry of Education also issued the guidelines related to culture and education.

The importance of culture and education, especially the traditional culture and education, has been discussed by many scholars in the academic circle, such as.

"excellent traditional culture and education is a good medicine for solving the spiritual and moral problems of modern society. Strengthening the education of excellent traditional culture is a necessary measure to strengthen the cultural identity of the Chinese nation in the face of multiculture.

\section{B. The importance of the thought of Dialectical Opposition to Culture and Education}

In the former part, the author introduces the relationship between dialectical opposition thought and Chinese culture. Practice is the only criterion to test truth. Whether dialectical opposition thought really has positive effect on culture education must be put into practice. Therefore, the author divides into two aspects to narrate the dialectical opposition thought in the concrete culture education practice the function.
1) Contribute to the study of Chinese traditional culture

In traditional Chinese culture, Zhouyi and Taoist thought are among the more difficult to teach, because this content is closely related to philosophy, and most of the textbooks only mention some of the ideas that have been summed up in a scribbled way. But if the teacher can explain to the students the application of Taoism and Zhouyi thought in the daily language phenomenon and use the relevant words as an introduction, it should reduce the students' resistance to the contents of the block and strengthen the students' sense of intimacy. Deepen students' understanding. Undoubtedly, to achieve these goals, we should rely on the help of dialectical opposition. At the same time, teachers should add the content of dialectical opposition when they teach Yin and Yang thought, so they can think that the content of teaching is more profound and philosophical, and it is not easy to fall into the superstitious tendency.

\section{2) Help to improve the appreciation of ancient art}

The influence of dialectical opposition on vocabulary has been described in detail in the preceding article. If we can guide students to understand dialectical opposition thought deeply, then students will be able to apply some laws of dialectical opposition thought consciously when they study ancient Chinese. In order to distinguish the diphonic rhyme and antithesis phenomenon in the ancient Chinese, such various forms of classical literature works will no longer be so uninteresting and boring to the students, but can be flexibly disassembled, so that the students can not only better understand the rhyme of the ancient Chinese prose, but also have a better understanding of the rhyme of the ancient Chinese prose. And even under the guidance of the law to consciously create couplets and drama creation, the current stage of cultural and educational experience is to lead students to copy and watch the relevant video; The author believes that only to guide students to create consciously in order to better enable them to experience the true essence of traditional culture, and have resonance with it. Under the guidance of this idea, students can better understand the spirit expressed by the author when they appreciate couplets, traditional Chinese paintings and ancient poetry, so they can have more insight.

\section{CONCLUSIONS}

As an important part of Chinese philosophy, the thought of dialectical opposition has exerted a profound influence on Chinese traditional culture, which is closely related to the language and mode of thinking of the Chinese nation. Nowadays, culture and education have been paid more and more attention by our country, the system of culture and education has been perfected, and the proportion of traditional culture and education in schools has become the mainstream. This kind of connection between dialectical opposition thought and traditional culture has been applied to the practice of culture and education. It can not only help students understand the Chinese culture and the unique mental outlook of the Chinese nation more deeply, but also improve the students' aesthetic appreciation of ancient art, so as to improve the quality of culture and education. 


\section{REFERENCE}

[1] Chen Ke-jiong. Unification of Heaven and Man and extension of the meaning of words: an introduction to Cultural lexicology [J]. 1994. (In Chinese)

[2] Wang Xinghua. Relativism is the core of Zhuangzi's philosophy [J], philosophical Research, 1981, 4. (In Chinese)

[3] Chang Jingyu. Chinese Vocabulary and Culture [M]. Beijing: Peking university press, 1995: 5.

[4] Wang Bi. Laozi Daode Jing Note, [M]. Beijing: Zhonghua Book Company, 2011.1. (In Chinese)

[5] Guo Haijun, Zhang Xudong. Chinese excellent traditional Culture Education and College Chinese course Construction [J]. Journal of Northeast normal University (philosophy and Social Sciences Edition), 2015 (3) (In Chinese)

[6] Yu Chunhai, Yang Hao, the main content and system construction of Chinese excellent traditional culture and education [J]. Chongqing Social Sciences, 2014,10. (In Chinese)

[7] Wu Genyou. On the Spirit of Chinese philosophy [J]. Jiangxi social sciences, 2008, 2002, 2 (In Chinese) 